\title{
HUBUNGAN POLA ASUH ORANG TUA DENGAN KECANDUAN GAME ONLINE PADA ANAK USIA REMAJA DI SMA KRISTEN ZAITUN MANADO
}

\author{
Juwi Rayfana Tiwa \\ O. I Palandeng \\ Jeavery Bawotong \\ Program Studi Ilmu Keperawatan Fakultas Kedokteran \\ Univeristas Sam Ratulangi \\ Email : juwitiwa@gmail.com
}

\begin{abstract}
Abstrack : Teenagers are ages who learn to try, both emotionally, spiritually, and socially and usually teenagers start looking for identity and associating with their environment. The role of parents is very important to guide and educate children. Teenagers are very interested in online games, if left unattended by parents, they will become addicted. Game addiction is a game that can give gamers a feeling of happiness to have a tendency to keep playing and ignore reality. The purpose of this study was to find out the relationship of parenting parents with online game addiction in adolescents in the Olives of Manado Senior High School. The research method uses cross sectional. The respondents consisted of 60 teenagers with a total sampling technique. Data collection uses parenting and online game addiction questionnaires. The Chi-square test results obtained were smaller than the significant values $(\alpha=0.05)$ in parenting parents with online game addiction $(\rho=0.021)$. The conclusion of the research shows that there is a correlation between parenting parents and online game addictions.
\end{abstract} Keywords: Parenting Parents, Addicted To Online Games, Teenagers

\begin{abstract}
Abstrak : Remaja adalah usia yang belajar mencoba, baik secara emosi, spiritual, maupun sosial dan biasanya usia remaja mulai mencari jati diri dan bergaul dengan lingkunganya. Peran orang tua sangatlah penting untuk membimbing dan mendidik anak. Remaja sangat tertarik dengan game online, jika di biarkan tanpa pengawasan orang tua, akan berdapak menjadi kecanduan. Kecanduan game adalah permainan game yang dapat memberikan perasaan bahagia terhadap gamer untuk memiliki kecenderungan terus bermain dan mengabaikan realitas. Tujuan penelitian ini adalah mengetahui hubungan pola asuh orang tua denga kecanduan game online pada anak usia remaja di SMA Kristen Zaitun Manado. Metode Penelitian menggunakan cross sectional. Responden terdiri dari 60 remaja dengan teknik pengambilan total sampel. Pengumpulan data menggunakan kuesioner pola asuh dan kecanduan game online. Hasil Uji Chi-square yang di dapatkan lebih kecil dari nilai signifikan $(\boldsymbol{\alpha}=0,05)$ pada pola asuh orang tua dengan kecanduan game online $(\boldsymbol{\rho}=0,021)$. Kesimpulan hasil penelitian menunjukkan terdapat ada hubungan antara pola asuh orang tua dengan kecanduan game online.
\end{abstract}

Kata kunci : Pola Asuh Orang Tua, Kecanduan Game Online, Remaja 


\section{PENDAHULUAN}

Game online merupakan salah satu pilihan untuk menghabiskan waktu sengang mulai dari anak-anak sampai orang dewasa. Di zaman era modern ini smartphone sudah bisa mengunduh aplikasi game online sehingga dapat digunakan dan dimainkan di mana saja, asalkan dapat terkoneksi dengan jaringan internet. Menurut Young (2009) Game online merupakan situs yang menyediakan berbagai macam jenis permainan yang dapat melibatkan beberapa pengguna internet di berbagai waktu tempat yang berbeda saling terhubung di waktu yang sama.

Data jumlah gamer di Indonesia yang tersedia hanya dikeluarkan oleh lembaga bisnis. Data terbaru, pada 2017, menurut lembaga riset pemasaran asal Amsterdam, Newzoo, ada 43,7 juta gamer (56\% diantaranya laki-laki) di negeri ini, yang membelanjakan total US\$ 880 juta. Jumlah pemain game Indonesia terbanyak di Asia Tenggara, yang bermain game di telepon pintar, personal computer dan laptop, serta konsul. Prevelensi kecanduan game dengan mengambil sampel di sekolah-sekolah di Manado, Medan, Pontianak, Yogyakarta pada tahun 2012. Menemukan bahwa 45,3\% dari 3.264 siswa sekolah yang bermain game online selama sebulan terakhir dan tidak berniat untuk berhenti (Retha Arjadi dalam Kompas.com).

Organisasi Kesehatan Dunia atau World Health Organizations (WHO) resmi menetapkan Kecanduan game atau game disorder ke dalam versi terbaru International Statistical Classification of Diseases (ICD) seebagai penyakit gangguan mental untuk pertama kalinya. ICD merupakan daftar klasifikasi medis yang dikeluarkan WHO berisi daftar penyakit berikut gejala, tanda, dan penyebabnya. ICD menjadi standar internasional untuk pelaporan penyakit dan kondisi kesehatan dan digunakan oleh seluruh praktisi kesehatan di dunia. Dalam versi terbaru ICD-11, WHO menyebut bahwa kecanduan game merupakan disorders due to addictive behavior atau gangguan yang disebabkan oleh kebiasaan atau kecanduan (Kementerian Kesehatan RI, 2018).

Data jumlah gamer di Indonesia yang tersedia hanya dikeluarkan oleh lembaga bisnis. Data terbaru, pada 2017, menurut lembaga riset pemasaran asal Amsterdam, Newzoo, ada 43,7 juta gamer (56\% diantaranya laki-laki) di negeri ini, yang membelanjakan total US\$ 880 juta. Jumlah pemain game Indonesia terbanyak di Asia Tenggara, yang bermain game di telepon pintar, personal computer dan laptop, serta konsul. Prevelensi kecanduan game dengan mengambil sampel di sekolah-sekolah di Manado, Medan, Pontianak, Yogyakarta pada tahun 2012. Menemukan bahwa 45,3\% dari 3.264 siswa sekolah yang bermain game online selama sebulan terakhir dan tidak berniat untuk berhenti (Retha Arjadi dalam Kompas.com).

Menurut Halawa \& Christopher (2017) menyatakan dalam mewujudkan perilaku disiplin yang baik pada remaja, peran orang tua dalam memberikan pola asuh yang baik dan sesuai dengan karakter remaja menjadi sangat penting untuk dilakukan. Pemahaman mengenai cara mendidik dan menanamkan konsep yang baik mengenai kedisiplinan pada remaja serta didukung oleh pemahaman akan karakter remaja lewat pemberian perhatian dan komunikasi intens yang terjadi di dalam keluarga menjadi hal penting yang harus dipahami orang tua dalam mengajarkan kedisiplinan pada remaja.

Sukrakarta (2014) menyatakan keluarga khususnya orangtua memegang peranan penting dalam membentuk sikap dan perilaku anak. Berbagai permasalahan dapat mempengaruhi minat dan anak untuk mengikuti kegiatan belajar di sekolah. Remaja yang mengalami kecanduan game online tidak terlepas dari beberapa faktor. Smart (2010) mengemukakan bahwa faktorfaktor yang dapat mengakibatkan kecanduan game online adalah kurang perhatian dari orang-orang terdekat, mengalami stress, kurang kontrol orangtua, kurang kegiatan, lingkungan, dan pola asuh orangtua yang salah. Pola asuh orangtua menjadi salah satu 
faktor penyebab remaja mengalami kecanduan game online.

\section{METODE PENELITIAN}

Penelitian ini termasuk dalam jenis penelitian kuantitatif dengan menggunakan metode penelitian survei analitik untuk menganalisis perbedaan antara 2 variabel yaitu variabel independen (pola asuh orang tua) dan variabel dependen (kecanduan game online). Penelitian ini menggunakan desain penelitian cross sectional.

Penelitian ini dilaksanakan di SMA

Kristen Zaitun Manado pada tanggal 17 Januari 2019. Populasi penelitian ini adalah 72 orang. Pengambilan sampel menggunakan teknik total sampling dan mendapatkan sampel 60 orang yang masuk kriteria inklusi. Instrument penelitian yang digunakan untuk mengukur pola asuh orang tua menggunakan kuesioner yang pernah digunakan sebelumnya oleh Devi, C (2012). Kuesioner yang digunakan dalam penelitian ini terdiri dari 16 pertanyaan. Dengan kategori penilain yaitu skore $\leq 40$ tidak demokratis, dan demokratis $\geq 40$. Instrument penelitian yang digunakan untuk mengukur kecanduan game online 40 pertanyaan yang digunakan dalam penelitian sebelumnya Fransisca, G.B. (2015). Dengan kategori penilain yaitu skore $\leq 120$ terkontrol, dan tidak terkontrol $\geq 120$. Setelah lembar kuesioner diisi oleh responden, peneliti mengumpulkan kembali lembar kuesioner.

Pengolahan data yang diperoleh dari hasil penelitian ini dianalisis menggunakan uji statistik melalui sistem komputerisasi dengan beberapa tahap yaitu editing, coding, tabulasi data (Notoatmodjo, 2010). Analisa bivariat dalam penelitian ini yaitu untuk mengetahui hubungan pola asuh orang tua dengan kecanduan game online. Peneliti menggunakan uji Chi Square dengan tingkat kemaknaan 95\% $(\alpha=0,05)$.
HASIL dan PEMBAHASAN

1. Karakteristik Responden

Tabel 1. Distribusi Responden Berdasarkan Jenis Kelamin

\begin{tabular}{ccc}
\hline Jenis Kelamin & N & \% \\
\hline Laki-laki & 55 & 47,8 \\
Perempuan & 60 & 52,2 \\
\hline Total & $\mathbf{1 1 5}$ & $\mathbf{1 0 0}$ \\
\hline Sumber $:$ Data Primer 2019 &
\end{tabular}

Sumber : Data Primer 2019

Hasil penelitian laki-laki lebih cenderung menunjukkan tingkat keterhubungan internet dan penggunaan bermain game online yang lebih tinggi dari pada perempuan (Jiang, 2014). Laki-laki juga banyak merasa bahwa game online merupakan hiburan yang membuat mereka bahagia dengan tantangan-tantangan yang ada di game online, bisa juga mendapatkan prestasi sehingga menjadikan game tempat pelarian dari kejenuhan. Adapun Hasil penelitian yang di lakukan menunjukkan bahwa $90,6 \%$ dari pecandu berjenis kelamin laki-laki. Hal ini sesuai dengan penelitian yang dilakukan oleh pusat studi Stanford University School of Medicine pada tahun 2008 yang menyatakan bahwa laki-laki lebih mudah kecanduan pada online game dari pada wanita (Puspitosari \& Amanta, 2009).

Tabel 2. Distribusi Responden Berdasarkan Usia

\begin{tabular}{ccc}
\hline Usia & $\mathbf{N}$ & $\%$ \\
\hline 15 tahun & 5 & 8,3 \\
16 tahun & 25 & 43,3 \\
17 tahun & 29 & 48,3 \\
\hline Total & $\mathbf{6 0}$ & $\mathbf{1 0 0 , 0}$
\end{tabular}

Sumber : Data Primer 2019

Hasil penelitian menggambarkan bahwa sampel yang mendapatkan menunjukkan bahwa sebagian besar sampel memiliki usia yaitu 17 tahun sebanyak 44 orang (48,3\%). Menurut Sa'id, A. (2017) Pada masa remaja madya ini sebagai masa mencari sesuatu yang dapat dipandang bernilai, pantas diunjung tinggi dan dipujapuji sehingga masa ini disebut masa merindu puja (mendewa-dewakan), yaitu sebagai gejala remaja. Hal ini juga di temukan pada 
penelitian Ibrahim, M. (2014) yaitu umur remaja 15-17 tahun yang lebih dominan kecanduan game online.

Tabel 3. Distribusi Responden Berdasarkan Pekerjaan Orang Tua

\begin{tabular}{lll}
\hline $\begin{array}{l}\text { Pekerjaan } \\
\text { Orang Tua }\end{array}$ & n & \% \\
\hline $\begin{array}{l}\text { Dokter } \\
\text { Ibu Rumah }\end{array}$ & 1 & 1.7 \\
Tangga & & 16.7 \\
Penginjil & 1 & 1.7 \\
Petani & 17 & 28.3 \\
Swasta & 31 & 51.7 \\
\hline Total & $\mathbf{6 0}$ & $\mathbf{1 0 0 , 0}$ \\
\hline
\end{tabular}

\section{Sumber : Data Primer 2019}

Hasil penelitian menggambarkan bahwa sebagian besar sampel memiliki pekerjaan orang tua yaitu swasta 31 orang $(51,7 \%)$, pekerjaan petani sebanyak 17 orang $(28,3 \%)$, ibu rumah tangga 10 orang $(16,7 \%)$, penginjil 1 orang $(1,7)$, dan dokter 1 orang $(1,7 \%)$. Dalam penelitian Ulfah (2016) tidak terdapat pengaruh yang signifikan antara pola asuh orang tua yang bekerja terhadap perkembangan kepribadian remaja. Namun orang tua yang sering lebih mementingkan pekerjaan dan menghabiskan waktu dengan pekerjaan sehingga membiarkan anak dan tidak menyediakan waktu untuk mendidik anak bahkan cenderung lebih membiarkan melakukan apa saja tanpa ada komunikasi yang baik antara orang tua dengan anak.

Tabel 4. Distribusi Responden Pendidikan Orang Tua

\begin{tabular}{ccc}
\hline $\begin{array}{c}\text { Pekndidikan } \\
\text { Orang Tua }\end{array}$ & n & \% \\
\hline S1 & 2 & 3.3 \\
SD & 4 & 6.7 \\
SMP & 16 & 26.7 \\
SMA & 38 & 63.3 \\
S1 & 2 & 3.3 \\
\hline Total & $\mathbf{6 0}$ & $\mathbf{1 0 0 , 0}$ \\
\hline
\end{tabular}

Sumber: Data Primer 2019

Hasil penelitian menunjukkan bahwa sampel yang mendapatkan sampel memiliki pendidikan orang tua yaitu SMA 38 orang
(63,3\%). Dalam hasil penelitian Sadani, (2017) hubungan positif dan signifikan tingkat pendidikan orang tua terhadap hasil belajar siswa. Dan dengan kata lain bahwa semakin baik tingkat pendidikan orang tua maka pola asuh akan meningkat. Orang tua dengan pedidikan yang tinggi akan mempengaruhi pola asuh dan prestasi anak melalaui ajaran orang tua. Ditemukan dalam penelitian Kharisma (2011) ada pengaruh positif dan signifikan, pengaruh tingkat pendidikan orang tua terhadap Pola Asuh di Desa Losari Kidul Kecamatan Losari Kabupaten Brebes sebesar 19.1\%. sedangkan prosentasi sisanya sebesar $80,9 \%$ dipengaruhi oleh faktor-faktor lainya. Tetapi dalam beberapa kasus tingkat pendidikan yang tinggi belum tentu dapat menjamin anaknya dapat berprestasi dengan baik dalam belajar (Marhento, 2011). Karena meskipun pendidikan orang tua yang tinggi namun kurangya interaksi orang tua terhadap anak, dan kurang kontrol dan didikan akan sama sekali tidak mempengaruhi pola asuh.

\section{Analisa Univariat}

Tabel 5. Distribusi Responden Pekerjaan Pola Asuh

\begin{tabular}{ccc}
\hline Pola asuh & n & \% \\
\hline Demokratis & 31 & 51,7 \\
Tidak Demokratis & 29 & 48,3 \\
\hline Total & $\mathbf{6 0}$ & $\mathbf{1 0 0 , 0}$ \\
\hline
\end{tabular}

Sumber: Data Primer 2019

Hasil penelitian sampel mendapatkan pola asuh demokratis yaitu sebanyak 31 sampel $(51,7 \%)$ dan sisanya tidak demokratis yaitu sebanyak 29 sampel $(48,3 \%)$. Menurut Wong, (2009) Kontrol orang tua kuat dan konsisten tetapi disertai dengan dukungan, pengertian, dan keamanan. Kontrol difokuskan pada masalah, tidak pada penarikan rasa cinta atau takut pada hukuman. Pola asuh demokratis adalah pola asuh yang memprioritaskan kepentingan anak, akan tetapi tidak ragu-ragu mengendalikan mereka. Orang tua dengan pola asuh ini bersikap rasional, selalu mendasari tindakan pada rasio atau pemikiran-pemikiran. Orang tua tipe ini bersikap realistis terhadap 
kemampuan anak, tidak berharap yang berlebihan yang melampaui kemampuan anak (Djamarah, 2014).

Tabel 6. Distribusi Responden Kecanduan Game Online

\begin{tabular}{lll}
\hline $\begin{array}{l}\text { Kecanduan } \\
\text { Game Online }\end{array}$ & $\mathbf{n}$ & $\mathbf{\%}$ \\
\hline Terkontrol & 33 & 55,0 \\
Tidak Terkontrol & 27 & 45,0 \\
\hline Total & $\mathbf{6 0}$ & $\mathbf{1 0 0 , 0}$ \\
\hline Sumber: Data Primer 2019 &
\end{tabular}

Sumber: Data Primer 2019

Hasil penelitian menggambarkan bahwa sebagian besar sampel mendapatkan kecanduan game online yang terkontrol yaitu sebanyak 33 sampel $(55,0 \%)$ dan tidak terkontrol yaitu sebanyak 27 sampel $(45,0 \%)$. Bermain game online memiliki kesenenagan tersendiri bagi mereka yang senang dengan game, sehingga membuat ketagihan untuk bermain, menyelesaikan permainan, mencapai skore tertinggi ataupun level tertentu. Sehingga game online dapat membuat kecanduan bermain game online.

\section{Analisa Bivariat}

Tabel 7. Hubungan Pola Asuh Orang Tua Dengan Kecanduan Game Online

\begin{tabular}{ccccc}
\hline & \multicolumn{2}{c}{ Kecanduan Game } & & P- \\
Pola Asuh & \multicolumn{3}{c}{ Online } & $\begin{array}{c}\text { P- } \\
\text { Orang Tua }\end{array}$ \\
\cline { 2 - 3 } & Terkontrol & $\begin{array}{c}\text { Tidak } \\
\text { Terkontrol }\end{array}$ & & \\
Demokratis & 22 & 9 & 31 & \\
$\begin{array}{c}\text { Tidak } \\
\text { Demokratis }\end{array}$ & 11 & 18 & 29 & 0,021 \\
\hline Total & $\mathbf{3 3}$ & $\mathbf{2 7}$ & $\mathbf{6 0}$ & \\
\hline
\end{tabular}

Sumber: Data Primer 2019

Hasil penelitian menunjukan sampel dari pola asuh orang tua demokratis 31 orang dengan kecanduan game online 22 orang terkontrol dan 9 orang tidak terkontrol, pola asuh orang tua tidak demokratis 29 orang dengan kecanduan game online 11 orang terkontrol dan 18 orang tidak terkontrol. Hasil uji hipotesis dengan menggunakan uji Chi Square dengan tingkat kepercayaan 95\% $(\alpha 0,021)$, menunjukan adanya hubungan pola asuh orang tua dengan kecanduan game online pada anak usia di SMA Kristen Zaitun
Manado. Dimana nilai $\mathrm{p}=0,021$ lebih kecil dari $\alpha=0,05$.

Penelitian Amin \& Harianti (2019) terdapat bahwa pola asuh orang tua demokratis juga dapat menyebabkan kecanduan game online pada anak. Anakpun bisa melakukan kegiatan apapun karena anak merasa orang tua memberikan kesempatan untuk mengembangkan diri namun, apabila Jika anak kurang kontrol dari orang tua anak pun bisa melakukan hal-hal yang tidak di duga karena terlalu percaya dan tidak di imbangi lagi dengan kontrol orang tua.

Hasil penelitian ini sejalan dengan hasil penelitian oleh Triswahyuning, (2019) ada hubungan pola asuh orang tua dengan kecanduan game online, mengalami kecanduan game online karena dari paparan para subyek serta paparan dari orang tua dan guru bimbingan sekolah. Hal ini yang di temukan juga dalam penilitian Santoso, (2013) bahwa ada beberapa faktor yang salah satunya adalah faktor pola asuh orang tua yang dapat membuat anak kecanduan game online. Penelitian Ganetya, (2016) Peranan orang tua dalam upaya mengatasi kecanduan game online menjadi penting karena anak menjadi mudah memahami apa yang ingin orang tua terapkan kepada mereka. Dari hasil penelitian ini ada hubungan antara pola asuh orang tua dengan kecanduan game online, tetapi juga pola asuh orang tua juga berperan penting untuk mengatasi kecanduan game online.

\section{SIMPULAN}

Penelitian ini tentang hubungan pola asuh orang tua dengan kecanduan game online pada usia remaja di SMA Kristen Zaitun Manado. Didapatkan pola asuh orang tua yang paling banyak diterapkan adalah pola asuh demokratis. Kecanduan game online paling banyak masih terkontrol. Dan Ada hubungan pola asuh orang tua dengan kecanduan game online pada usia remaja di SMA Kristen Zaitun Manado. 
DAFTAR PUSTAKA

Amin, S. \& Harianti, R. (2018). Pola Asuh Orang Tua Motivasi Belajar Anak:Deepublish. Yogyakarta.

Devi, W, C. (2012). Hubungan Pola Asuh Orang Tua Dengan Kecerdasan Sosial Pada siswa Kelas VI SD Jatimulyo 01

Djamarah. (2014). Pola Asuh Orang Tua dan Komunikasi dalam Keluarga. Jakarta: PT Rineka Cipta.

Fransisca, G.B. (2015). Perbedaan Tingkat Kecanduan Game Online Pada Remaja Antar Gaya Pengasuhan

Ganestya, K. (2016). Peranan Orang Tua Dalam Upaya Mengatasi

Kecanduan Game Online Siswa SMP Negeri 20 Malang. http://mulok.library.um.ac.id/index 3.php/78639.html

Halawa, A., Christopher, J,. (2017). Hubungan Pola Asuh Orang Tua Terhadap Kedisiplinan Remaja Di Smpk Santo Vincentius Surabaya.

Ibrahim, M. (2014). Kecamatan, D. I., Kota, K., Psikologi, F., Islam, U Hubungan kecanduan game online dengan keterampilan sosial remaja di 4 game centre di kecamatan klojen kota malang.

Jiang, Q. (2014). Internet addiction among young people in China: Internet connectedness, online gaming, and academic performance decrement.

Internet Research, 24(1), 2-20.

Kecanduan Game Online Pada Peserta Didik Kelas X di Madrasah Aliyah Al Furqon Prabumulih Tahun Pelajaran 2015/2016. Bimbingan Dan Konseling, 03(1),

153-169.
http://doi.org/10.24042/KONS.V3I2 75

Kementerian Kesehatan RI, (2018 Juni). Kemenkes: Kecanduan Game Adalah Gangguan Perilaku. Di ambil dari http://www.depkes.go.id/article/p rint/18062500003/kemenkeskecan dua ngame -adalah-gangguanperilaku.html

Kharmina, N. (2011). Hubungan Antara Tingkat Pendidikan Orang Tua Dengan Orientasi Pola Asuh Anak Di Desa Losari Kidul Pendidikan Kecamatan Losari Kabupaten Brebes

Marhento, G. (2011). Pengaruh Tingkat Pendidikan Dan Pola Asuh Orang Tua Terhadap Prestasi Belajar IPA

Notoatmodjo (2010). Metodologi Penelitian Kesehatan. Jakarta: Rineke Cipta

Retha Arjadi, (2015, Februari) Adiksi Game Online pada Remaja dan Cara Bijak Menyikapinya. Di ambil dari https://sains.kompas.com/read/2015/ 02/11/200000523/adiksi-gameonline- pada-remaja-dancara-bijak-menyikapinya.

Puspitosari, W. A., \& Ananta, L. (2009). Hubungan antara Kecanduan Online Game dengan Depresi Correlation between Online Game Addiction with Depression. Mutiara Medika, 9(1), 50-56.

Sa'id, M, A. 2017. Buku Pintar Mendidik Remaja. Semesta Hikmah:Prambanan Klaten 
Sadani, K. R. (2017). Hubungan Tingkat Pendidikan Dan Pola Asuh Orang Tua Dengan Hasil Belajar Siswa, 6(15), 18.

Santoso, T. W. (2013). Perilaku KecanduanPermainan Internet dan Faktor Penyebabnya pada Siswa Kelas VIII. Indonesian Journal of Guidance and Counseling, 2(2), 5963

Smart, A. 2010. Cara cerdas mengatasi anak kecanduan game. Jogjakarta: A Pluss Books.

Surakarta, U. M. (2014). Hubungan Pola Asuh Otoriter Dan Intensitas Bermain Game Online Dengan Perilaku Bullying Pada Remaja Di Sekolah.

Tim Internet Sehat (2015, Januari) Ratarata Dua Jam Dihabiskan Anakanak Untuk Main Game. Di ambil dari http://internetsehat.id/2015/01/ra ta-rata-dua- jam-dihabiskananak-anak- untuk-main-game/

Triswahyuning, I. (2019) Kecanduan Game Online Siswa SMA Negeri 1 Gurah

Ulfah, M. (2015) Pengaruh Pola Asuh Orang Tua Yang Bekerja Terhadap Perkembangan Kepribadian Remaja Di SMA KH. Dewantoro, Pinang Kota Tangerang

Wong, D.L (2009). Buku Ajar Keperawatan Pediatric. Edisi 6. Volume 1. Jakarta: EGC

Young, K. (2009). Understanding Gaming Addiction. Center For Internet Addiction Recovery. 